Article

\title{
Ion Charge Influence on the Molecular Structure of Polyethylene Terephthalate Films after Irradiation with Swift Heavy Ions
}

\author{
Adil Z. Tuleushev ${ }^{1}$, Maxim V. Zdorovets ${ }^{2,3,4, *(D)}$, Artem L. Kozlovskiy ${ }^{2,3(1)}$ \\ and Fiona E. Harrison ${ }^{2}$ \\ 1 Flerov Laboratory of Nuclear Reactions, Joint Institute for Nuclear Research, 141980 Dubna, Russia; \\ adilzht@mail.ru \\ 2 Engineering Profile Laboratory, L.N. Gumilyov Eurasian National University, \\ Nur-Sultan 010008, Kazakhstan; kozlovskiy.a@inp.kz (A.L.K.); fiona_e_harrison@hotmail.com (F.E.H.) \\ 3 The Institute of Nuclear Physics, Almaty 050032, Kazakhstan \\ 4 Department of Intelligent Information Technologies, Ural Federal University, 620075 Yekaterinburg, Russia \\ * Correspondence: mzdorovets@inp.kz
}

Received: 29 April 2020; Accepted: 3 June 2020; Published: 4 June 2020

check for updates

\begin{abstract}
We report here experimental results investigating the influence of the initial swift heavy ion charge on the structure of polyethylene terephthalate (PET) film after irradiation, using a structurally sensitive $X$-ray diffraction method. Kr ions with an energy of $100 \mathrm{MeV}$ and charges of $13^{+}, 14^{+}$, and $15^{+}$ were each used at irradiation fluences of $5 \times 10^{10}, 7.5 \times 10^{10}, 1 \times 10^{11}, 2.5 \times 10^{11}$ and $5 \times 10^{11}$ ions $/ \mathrm{cm}^{2}$. At constant energy and irradiation fluence, the post-irradiation structural changes in PET film show a clear dependence on the initial ion charge. As either the fluence or ion charge increase, the latent tracks begin to overlap, leading to cross-linking of PET chain molecules to form rotational isomers (rotamers). We use the fluence corresponding to the onset of overlapping to estimate the size of latent tracks for different ion charges. At the highest fluences, the latent tracks become entirely overlapped, and the interchain cross-linking extends throughout the whole film. Since this cross-linking is due to the dipole-dipole interaction of subunits of repeat units of PET chain molecules, it is reversible, in contrast to the well-known chemical cross-linking of polymer chain molecules under irradiation.
\end{abstract}

Keywords: polyethylene terephthalate; ion charge; induced ordering; cross-linking; size of latent tracks; rotamers

\section{Introduction}

Polyethylene terephthalate (PET) films have been the subject of much study for a long time, both in their applied [1-10] and theoretical aspects [11-17]. A significant recent discovery [18,19] was that of ultrafast filtration with high selectivity by thin PET films irradiated with swift heavy ions, comparable to those for biological membranes. These studies showed that PET films irradiated with swift heavy ions and then UV-illuminated over a long time acquire the ability to filter ions with very high selectivity: up to $10^{8}$ times for cations over anions; up to $10^{6}$ times for alkali metal cations over heavy metal cations; and up to $10^{3}$ times for alkali metal cations over alkaline earth metal cations. Increasing the duration of the UV-illumination leads to a significant increase (up to 40 times) in the ionic conductivity of the PET film.

The high cationic selectivity observed in experiments is explained as follows in [18-21]. The core of the latent track closest to the swift heavy ion trajectory contains highly damaged fragmented material as a result of amorphization and the breaking of covalent chemical bonds by the swift heavy ion. When submerged in the electrolyte, some of these small fragments wash out leading to a 
reduced mass density in the core. Carboxyl units are one of the products of radiolysis and subsequent photodegradation of damaged molecules in the latent track, but in contrast to other small fragments, they attach to chain PET molecules and accumulate on the inner wall of the latent track, forming a network of negative charge in the highly damaged core of the latent track.

We agree with the authors of [19] who note that there is still room for further research to better understand these results. As shown in References $[18,19]$ the key factors affecting the high selectivity and permeability of PET films are the increased density of carboxyl units on the inner walls of the latent track and the reduced density of the material in the core. In Reference [22] we reported the emergence of regions of induced ordering in latent tracks in PET films after irradiation with swift heavy ions, as a result of rotation of benzene-carboxyl subunits of repeat units of chain molecules in the amorphous part of PET under the influence of the residual electric field of the latent track. Since the residual electric field has cylindrical symmetry, and dipoles always align with the field gradient, this rotation leads to the initially random distribution of carboxyl ions relative to the axis of the chain molecule in the amorphous phase of the film being replaced by an ordered distribution of carboxyl dipoles in the radial direction. This results in an increased density of carboxyl units on the inner walls of the latent track, without the irradiated film being introduced into water or an aqueous electrolyte.

The predominant ordering of benzene-carboxyl units in the radial direction leads to their ordering in the axial direction, due to the coplanarity of the subunits (see Section 2.1 below). This causes the random distribution of the orientation of benzene rings around the axis of the chain molecules to become predominantly oriented along the latent track axis to the same extent that the carboxyl groups are oriented along the residual field gradient, creating an axial texture along the latent track axis. The presence of this axial texture implies the existence of nanopores between neighboring rotated subunits. If the induced ordering were sufficiently high, the density of these nanopores would be high enough for them to merge into nanochannels along the axis of the track. These would form additional paths for the movement of the water electrolyte through the film in addition to the mechanism described in $[18,19]$.

Since this induced ordering is essentially determined by the residual electric field in the irradiated PET film, we now turn our attention to the nature and origin of this residual electric field.

In Bethe's formula for the energy loss of fast charged particles in matter [23], the 'effective charge' $Z^{\text {eff }}$ is one of the parameters that affects energy losses and, consequently, the response of the irradiated material. Bethe and Ashkin note here that calculations of energy losses using this formula will depend very sensitively on the law chosen for the decrease of the effective charge as the velocity of the particle decreases.

In many studies of irradiation of materials by swift heavy ions it is assumed that on penetration, the ion interacts immediately with the electrons in the material in such a way that $Z^{\text {eff }}$ is determined only by the irradiated material, to the extent that the initial ion charge is often considered so irrelevant as not to be mentioned [24-28].

PET is an industrially used electret that can store an externally induced electric field for a long time [29]. We therefore take as our hypothesis that swift ions moving through PET films are specific external sources of electric field that change the state of the electron subsystem of the film material. In addition to the ion energy, the ion charge can therefore contribute to the formation of a residual electric field in the latent track and affect post-irradiation changes of the molecular structure in PET films.

To test our hypothesis, we make use of our previous experimental results [30] showing that the overlapping of the residual electric fields of neighboring latent tracks leads to the formation of interchain spiral conformations. These interactions, and the spiral conformations they create, are sensitive to the degree of overlap of the residential electric fields and can, therefore, be used to investigate the characteristics of latent tracks and their dependence on external parameters including the initial charge of the irradiating ions. In this article, we report the results of our study. 


\section{Experimental Part}

\subsection{Material}

A $12 \mu \mathrm{m}$ polyethylene terephthalate film (HOSTAPHAN@polyester films, Mitsubishi Polyester Film GmbH, Wiesbaden, Germany) was selected for irradiation. According to the datasheet specifications, the PET film consists of an inner layer of pure polymer and thin outer layers containing additives that change the surface properties depending on the purpose of the film. In the production of films, a polymer with an average molecular weight of 20,000-30,000 amu is used (for methods of polymer analysis, see e.g., [31]). To ensure the purity of the experimental methodology, we conducted an X-ray diffraction study of the film sample that was subsequently irradiated. The information describing the PET film under study is given below (see Figure 1).

From the physical point of view, the PET film is a transparent semi-crystalline polymer with a density of $1.4 \mathrm{~g} / \mathrm{cm}^{3}$ with monomer density of $1.33 \mathrm{~g} / \mathrm{cm}^{3}$ and density of its crystalline part of $1.49 \mathrm{~g} / \mathrm{cm}^{3}$ [32]. For the polymer film under study, the ratio between the amorphous and crystalline parts derived from the X-ray image is $57 / 43$ (for the methodology of determining the ratio of the amorphous and crystalline phases, see e.g., [33]). The size of the crystallized particles is $8 \pm 2 \mathrm{~nm}$. The type of crystal lattice is triclinic with the unit cell parameters $a=4.541 \AA, b=5.914 \AA, c=10.775 \AA$, $\alpha=99.88^{\circ}, \beta=118.57^{\circ}, \gamma=111.46^{\circ}$, which are slightly different from the reference values of PET crystalline parameters (see PDF-00-050-2275). The axis c of the unit cell coincides with the axis of the chain molecule. The ratio of the intensity of diffraction maxima $\mathrm{I}_{(-110)} / \mathrm{I}_{(100)}=0.07$ indicates a strong texturization of the film (the reference value $\mathrm{I}_{(-110)} / \mathrm{I}_{(100)}=0.66$ ) with a predominant orientation of the benzene rings in the crystalline phase parallel to the film surface, which is in good agreement with the data [34]. In the amorphous phase, the orientation of benzene rings relative to the axes of chain molecules is random.

a)

c)
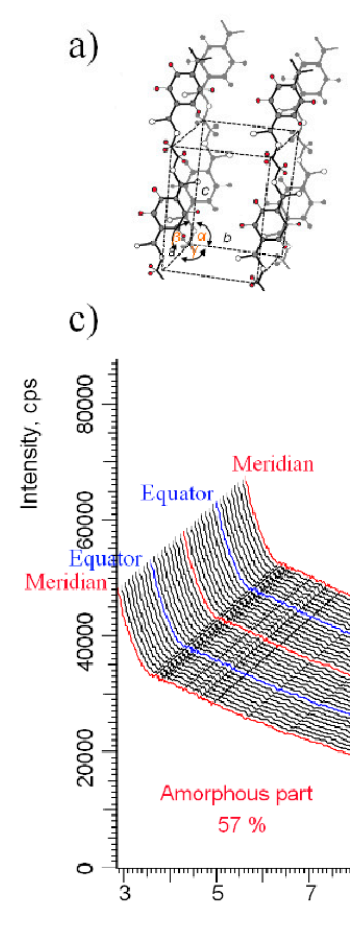
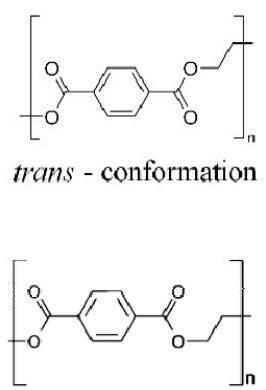

cis - conformation b)

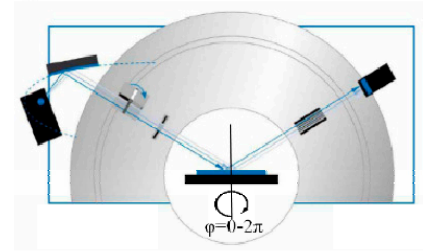

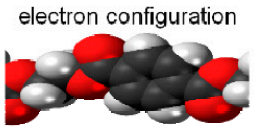
Crystalline part
$43 \%$

Intensity=constant Isotropic distribution

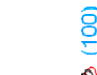

Figure 1. (a) Schematic representation of the PET crystalline lattice, its conformations and electron configuration; (b) Diagram of the X-ray diffractogram survey geometry; (c) X-ray diffractogram of the pristine PET sample in the $\phi=0-2 \pi$ geometry (blue lines show equator, red lines the meridian). 
From a chemical point of view, PET is a chain polymer, the repeat unit of which is shown in part (a) of Figure 1. The molecular weight of a repeat unit in both cis- and trans-conformations is $192 \mathrm{amu}$. Given that the parameter $\mathrm{c}$ of the PET unit cell is approximately $1 \mathrm{~nm}$, the length of chain molecules forming the film with a mass of 20,000-30,000 amu can exceed $100 \mathrm{~nm}$.

To date, it remains an open question as to what type of conformation the repeat units of PET polymer material are in. In the original work by Daubeny $R$., it was found that the trans-conformation is present in the crystalline part, while in [35] it was concluded that carboxyl units in unoriented PET are in trans- and cis-conformations with approximately equal probability, and in [36] it was suggested that there is a cis-conformation in oriented amorphous phases.

In addition, it has been shown that the benzene-carboxyl conformation is essentially coplanar [32,37]. It has also been experimentally found that the benzene-carboxyl unit is coplanar in monomers [38,39]. Quantum mechanical calculations [40] have shown that as a result of the overlap of the $\pi$ orbits, the benzene-carboxyl unit in this position has a stable minimum of potential energy with a high rotational barrier.

\subsection{Irradiation Conditions}

${ }^{84} \mathrm{Kr}$ ions with an energy of $100 \mathrm{MeV}$ were chosen, so as to permit ion beams at three different ion charges, of $13^{+}, 14^{+}$and $15^{+}$. These were used to irradiate the film at an angle of $42^{\circ}$ to the surface, with irradiation fluences of $5 \times 10^{10}, 7.5 \times 10^{10}, 1 \times 10^{11}, 2.5 \times 10^{11}$, and $5 \times 10^{11} \mathrm{ions} / \mathrm{cm}^{2}$. The film was irradiated along the film texture coinciding with the direction of its movement during irradiation in order to maximize the electrical interaction between the residual electric field and the carboxyl dipole units of the repeat units of chain PET molecules.

The choice of ion charge while maintaining constant beam energy in our experiment is due to the limited technical capabilities of the DC-60 accelerator, namely the ratio of the magnetic field and frequency of the high frequency (HF) generator. In our accelerator, the field can be adjusted in the range from 1.2 to $1.65 \mathrm{~T}$, and the frequency of the $\mathrm{HF}$ generator varies from $12 \mathrm{MHz}$ to $17 \mathrm{MHz}$, so there are not many combinations of ion types and their charges available at constant energy.

For ${ }^{84} \mathrm{Kr}$ ions, three charges are available: $13^{+}, 14^{+}, 15^{+}$at an energy of $100 \mathrm{MeV}$. Table 1 shows the values of the magnetic field induction and frequency of the HF generator at which the ${ }^{84} \mathrm{Kr}$ ions were obtained for irradiation to be used in the experiment.

Table 1. Parameters of ${ }^{84} \mathrm{Kr}$ ion acceleration.

\begin{tabular}{ccccccc}
\hline & Ion & Charge & Energy, MeV/A & Energy, MeV & Field, T & HF, MHz \\
\hline 1 & ${ }^{84} \mathrm{Kr}$ & $15^{+}$ & 1.1905 & 100 & 1.25015 & 13.712 \\
\hline 2 & ${ }^{84} \mathrm{Kr}$ & $14^{+}$ & 1.1905 & 100 & 1.33943 & 13.712 \\
\hline 3 & ${ }^{84} \mathrm{Kr}$ & $13^{+}$ & 1.1905 & 100 & 1.4425 & 13.713 \\
\hline
\end{tabular}

With these parameters of the cyclotron and proper preparation of thee electron cyclotron resonance (ECR) source, pure beams of krypton ions with three charge values at constant energy were obtained by the DC-60 accelerator.

According to calculations in the Stopping and Range of Ions in Matter (SRIM) Pro 2013 software [41], the maximum path length of ${ }^{84} \mathrm{Kr}$ ions in PET polymer with a density of $1.4 \mathrm{~g} / \mathrm{cm}^{3}$ is $20.0-20.5 \mu \mathrm{m}$, which confirms that the energy of $100 \mathrm{MeV}$ for ${ }^{84} \mathrm{Kr}$ ions is sufficient for the passage of ions through the PET film in this irradiation geometry.

\subsection{Study of the PET Structure}

Studies of structural changes in the irradiated PET films were performed by X-ray diffraction (D8 Advance Eco, Bruker, Karlsruhe, Germany) in the Bregg-Brentano geometry (coupled TwoTheta/Theta) in the angular range of $2 \theta=3-30^{\circ}$, step $0.01^{\circ}$ and azimuthal sweep $\phi=0-2 \pi$ in increments of $10^{\circ}$, 
X-ray radiation Cu-K $\alpha, \lambda=1.54 \AA$, Voltage $-40 \mathrm{kV}$, Current $-20 \mathrm{~mA}$, spectrum acquisition time $2 \mathrm{~s}$. Each of the $X$-ray images presented in this work contains 37 slices where slice 1 coincides with slice 37 . This $\phi$ overlap was performed to confirm the absence of changes in the molecular structure of the test sample during a 360-degree survey.

Analysis of the degree of crystallinity as well as the phase composition of the initial sample was determined using the TOPAS v.5.0 (Diffraction Suite, Bruker AXS GmbH 2014, Billerica, MA, USA) software code based on the Rietveld method [42]. A schematic layout of the survey geometry is shown in Figure $1 b$. The X-ray diffraction pattern of the pristine PET sample in a $\phi=0-2 \pi$ sweep is shown in Figure 1c, where two individual regions can be distinguished: the amorphous part of the PET at $2 \theta=$ $3-15^{\circ}$ and the crystalline part characterized by two diffraction reflections $(-110)$ at $2 \theta=23^{\circ}$ and $(100)$ at $2 \theta=26^{\circ}$.

We note that the coordinate $\phi$ is polar: the constant intensity of the peak for all angles $\phi$ in Figure $1 \mathrm{c}$ demonstrates the polar isotropy of the test sample. The X-ray diffractometry of chain molecules has its own nomenclature: the direction along the texture is called the "meridian" and is indicated by a red line in X-ray diffraction images, while the direction perpendicular is called the "equator" and is indicated by a blue line [43]. For this reason, $X$-ray slices with angles $0^{\circ}, 180^{\circ}$ and $360^{\circ}$ in Figure $1 \mathrm{c}$ are highlighted in red and coincide with the direction of the meridian, and X-ray slices with angles $90^{\circ}$ and $270^{\circ}$ are indicated in blue and coincide with the direction of the equator.

\section{Results and Discussion}

The X-ray diffraction patterns obtained in the geometry $(2 \theta, \phi)$ for PET samples treated under the above conditions are presented in Figure 2 and Figures 4-7. Since we are interested in comparing the differences in these patterns, in the graphs in Figure 3 we have plotted the azimuthal intensity for each for the three ion charges (and the pristine film) at $2 \theta=5^{\circ}$ and $2 \theta=26^{\circ}$, for each of the five fluences.

Figure 2: Fluence of $5 \times 10^{10}$ ions $/ \mathrm{cm}^{2}$

The X-ray diffraction pattern for the lowest initial ion charge $\left(\mathrm{Kr}^{13+}\right)$ (Figure 2a, red lines Figure 3a below) exhibits the same qualitative features as those seen for $\mathrm{Ar}^{8+}$ ions at the lower two fluences used in [22]: a meridian reflection in the region $2 \theta=5-12^{\circ}$ showing induced ordering in the amorphous phase and an azimuthally isotropic diffraction ring at $2 \theta=26^{\circ}$ in the crystalline phase, indicating that each latent track is isolated from all others. Increasing the ion charge by one to $\mathrm{Kr}^{14+}$ for the same fluence (Figure 2b, Figure 3a blue lines) leads to a small azimuthal anisotropy in the diffraction reflection intensity at $2 \theta=26^{\circ}$. As shown in [30], the onset of this anisotropy indicates the formation of spiral conformations in overlapping regions of the residual electric fields of latent tracks in PET. This X-ray diffraction picture also shows an increase in the size of the induced ordering zone, with the meridional reflection increasing in length (from $2 \theta=5-12^{\circ}$ to $2 \theta=5-14^{\circ}$ ) and intensity, for which we currently have no explanation but might be elucidated via experiments at lower fluences. The $\mathrm{X}$-ray diffraction pattern for $\mathrm{Kr}^{15+}$ ions (Figure 2c, Figure 3a green lines) shows a clear azimuthal anisotropy in the intensity of the diffraction reflection at $2 \theta=26^{\circ}$, and a return of the meridional reflection to values of $2 \theta$ angular size and intensity similar to those for $\mathrm{Kr}^{13+}$.

Comparing these results with the results for $\mathrm{Ar}^{8+}$, where anisotropy began to emerge at a fluence of $1 \times 10^{12}$ ions $/ \mathrm{cm}^{2}$ (see Figure 3, [22]) and was well established at a fluence of $2 \times 10^{12}$ ions $/ \mathrm{cm}^{2}$ [30], we see that for $\mathrm{Kr}^{14+}$, anisotropy emerges at an irradiation fluence that is 20 times lower, indicating a notably stronger ordering effect for $\mathrm{Kr}^{14+}$ ions compared to $\mathrm{Ar}^{8+}$ ions.

The above interpretation of the X-ray diffraction patterns makes it possible to estimate the transverse dimensions of the latent tracks of $\mathrm{Ar}^{8+}$ and $\mathrm{Kr}^{14+}$ ions in PET. If we assume that the fluence at which we first see structural evidence of overlap is close to its actual onset, then the average distance between ion trajectories at this fluence provides an estimate of the transverse dimensions of the latent tracks. In the case of $\mathrm{Ar}^{8+}$, this assumption is supported by the fact that there was no evidence of overlap at two lower fluences [30]. For Kr ions, no experiments were performed for lower fluences so it is possible that the onset of overlapping starts at fluences lower than $5 \times 10^{10} \mathrm{ions} / \mathrm{cm}^{2}$, in which 
case this approach will underestimate the transverse dimensions of the latent tracks. This approach yields estimated values of the radii of latent tracks in PET of $5 \mathrm{~nm}$ for $\mathrm{Ar}^{8+}$ and $22 \mathrm{~nm}$ for $\mathrm{Kr}^{14+}$. These estimates are rather higher than the estimate of $3 \mathrm{~nm}$ for $\mathrm{U}$ ions reported in [44], but broadly align with those in $[45,46]$, which were derived from measurements of the radial etching rate of latent tracks after irradiation with heavier ions $(\mathrm{U}, \mathrm{Au}, \mathrm{Xe}$ ) of generally higher energies (in the range of 1 to $11.6 \mathrm{MeV} / \mathrm{u}$ ), which found radii of up to $100 \mathrm{~nm}$.

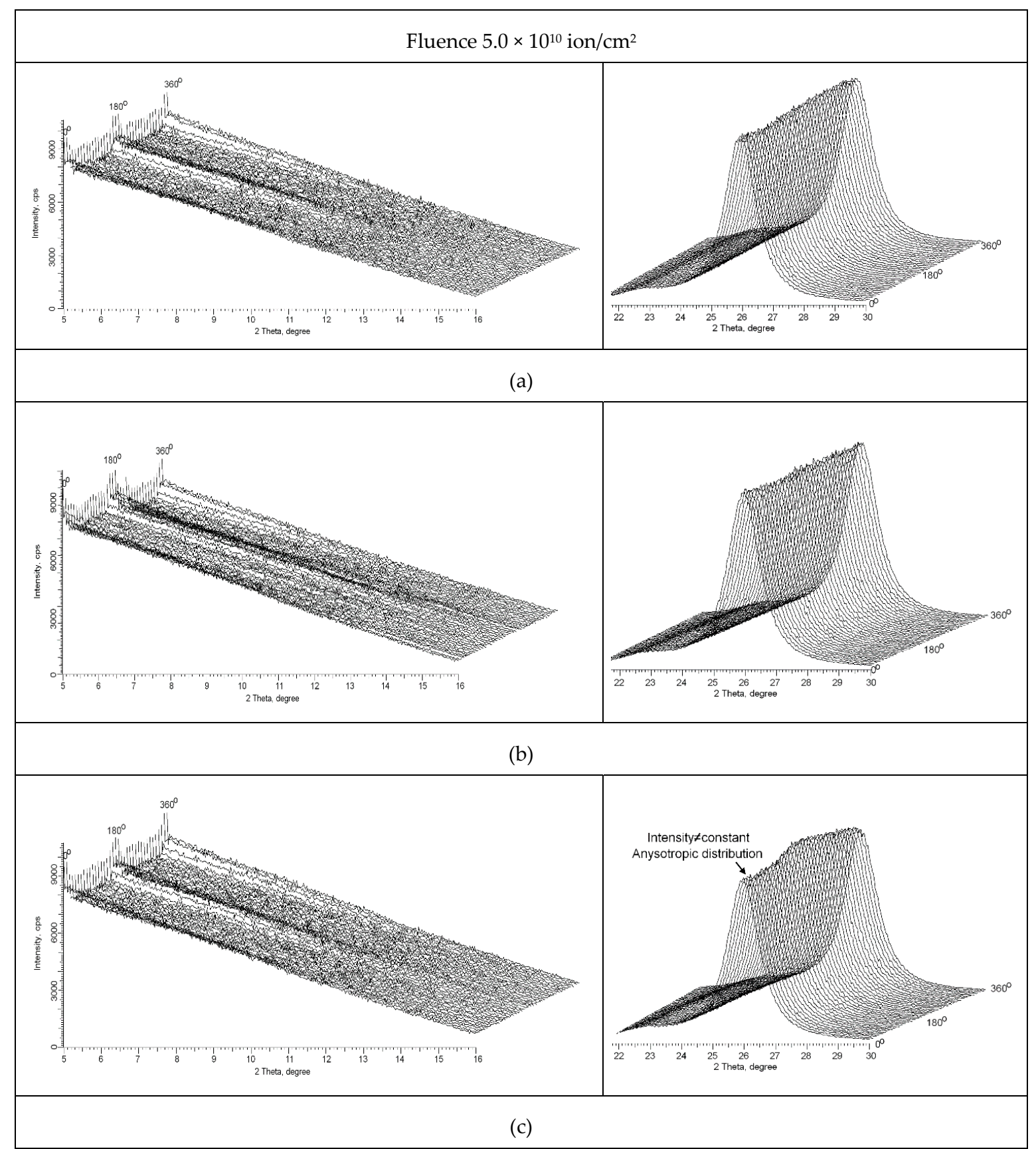

Figure 2. X-ray diffraction patterns of test samples polymer films: (a) irradiated $\mathrm{Kr}^{13+}$ ions; (b) irradiated $\mathrm{Kr}^{14+}$ ions; (c) irradiated $\mathrm{Kr}^{15+}$ ions for a fluence of $5 \times 10^{10}$ ions $/ \mathrm{cm}^{2}$.

Figures 4 and 5: Fluences of $7.5 \times 10^{10}$ ions $/ \mathrm{cm}^{2}$ and $1 \times 10^{11}$ ions $/ \mathrm{cm}^{2}$ respectively

At both these fluences, the $\mathrm{X}$-ray diffraction patterns for $\mathrm{Kr}^{13+}$ ions show a clear anisotropy in the intensity of the peak at $2 \theta=26^{\circ}$, with a greater anisotropy at the higher fluence (see also Figure $3 b, c$, 
red lines). Using the same assumptions and approach as previously, this leads to an estimate of $18 \mathrm{~nm}$ for the value of the radius of latent tracks for $\mathrm{Kr}^{13+}$ ions.

Perhaps surprisingly, for both $\mathrm{Kr}^{14+}$ and $\mathrm{Kr}^{15+}$ and at both fluences, the azimuthal anisotropy in the $\mathrm{X}$-ray reflection at $2 \theta=26^{\circ}$ has almost completely disappeared. In addition, the intensities of all four maxima at $2 \theta=26^{\circ}$ are practically the same, within the experimental noise limits (of approximately $200-300 \mathrm{cps}$ ), as are the intensities of the amorphous phase reflection at $2 \theta=5^{\circ}$ (see Figure $3 \mathrm{~b}, \mathrm{c}$, blue and green lines). This is despite the increases in both ion charge and fluence.

We believe that the most plausible explanation for this loss of the $\mathrm{X}$-ray signature of spiral conformations together with the absence of change in the intensities at $2 \theta=5^{\circ}$ and $2 \theta=26^{\circ}$ is as follows. Within the overlapping areas, the residual electric fields of latent tracks (which all share the same cylindrical symmetry) exert opposing, repulsive electrostatic forces, which are counterbalanced by mechanical forces due to elastic stresses in the polymer film. This is an inherently unstable situation, in which conformational isomers-rotational stereoisomers (rotamers) corresponding to local energy minima - exist in dynamic balance, interconverting on timescales that are far too short for resolution by X-ray diffraction. In such situations, X-ray diffractograms, which are effectively an integral over time, show only the response from the crystalline phase. Although rotamers in rapid dynamic equilibrium have no X-ray signature, their energy-absorbing presence would account for the constancy in the peak $\mathrm{X}$-ray intensities as the energy density increases.

The observed spiral conformations at lower energy densities are unusually stable rotamers, known as atropisomers, for which interconversion is hampered by restrictions on rotation [47], creating sufficiently large potential barriers between different rotamers that they exist long enough to be observed by X-ray diffraction methods. The disappearance of spiral conformations as the ion charge and fluence increase can then be understood as resulting from rotamer lifetimes dropping below the time of observation required for X-ray analysis.

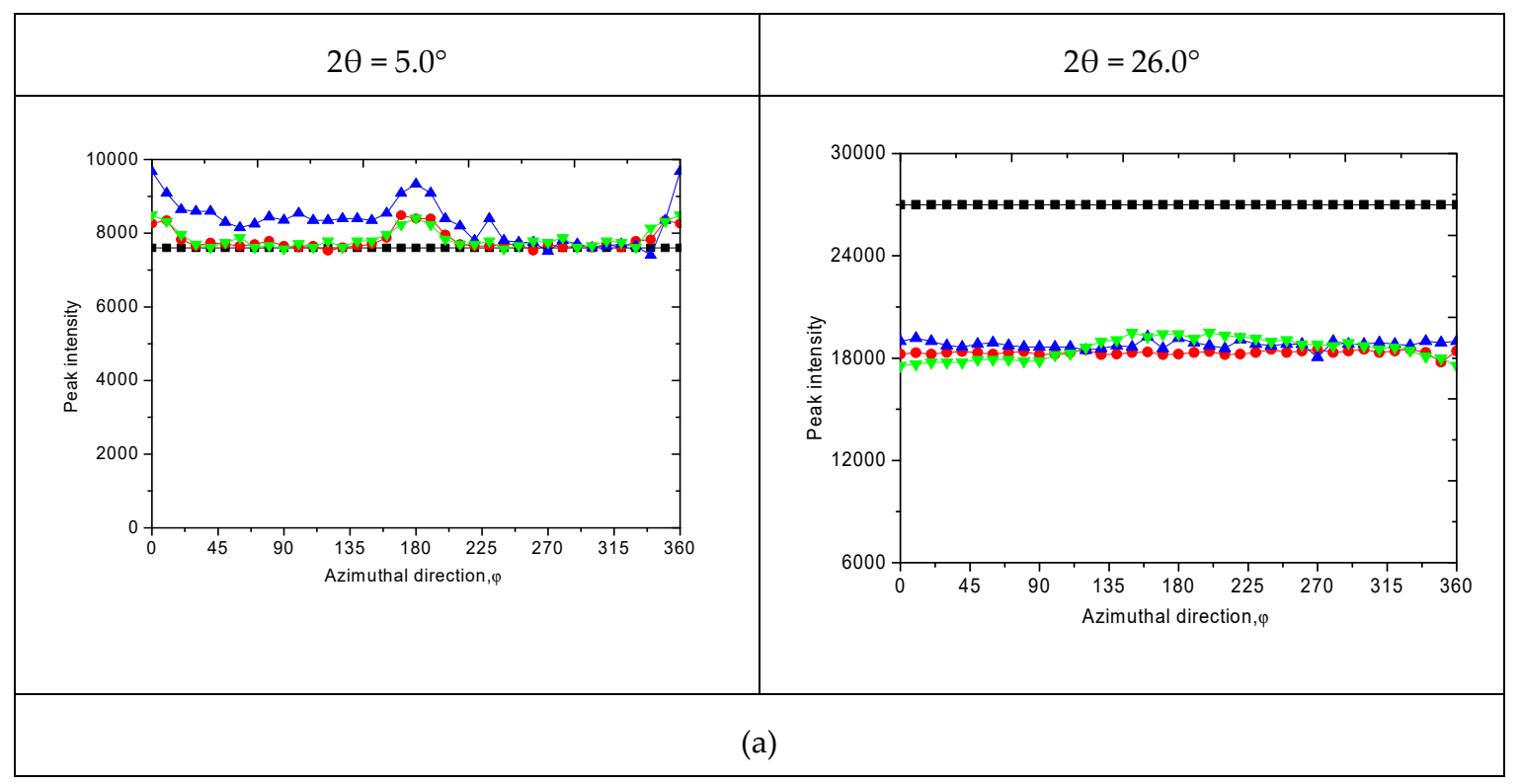

Figure 3. Cont. 


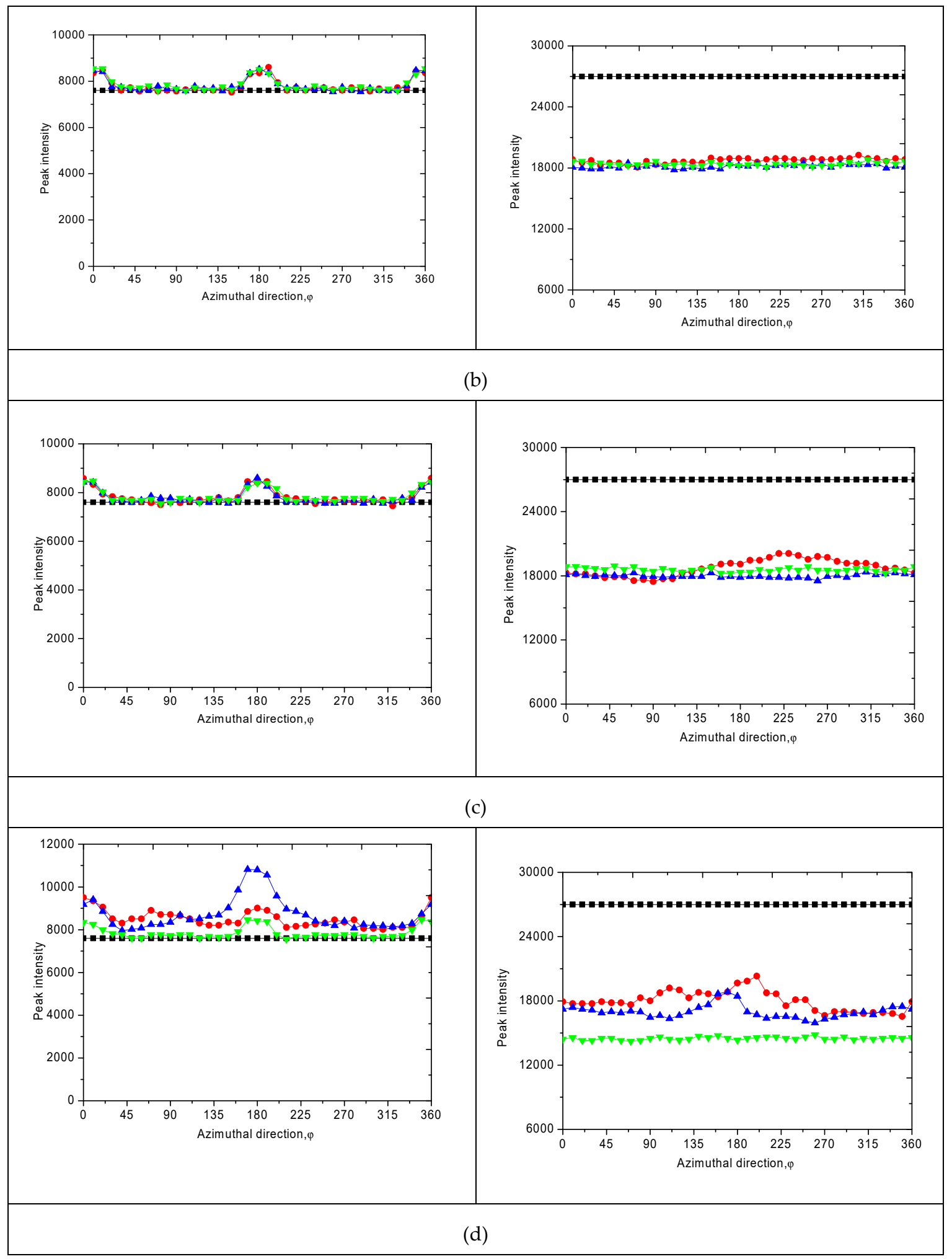

Figure 3. Cont. 


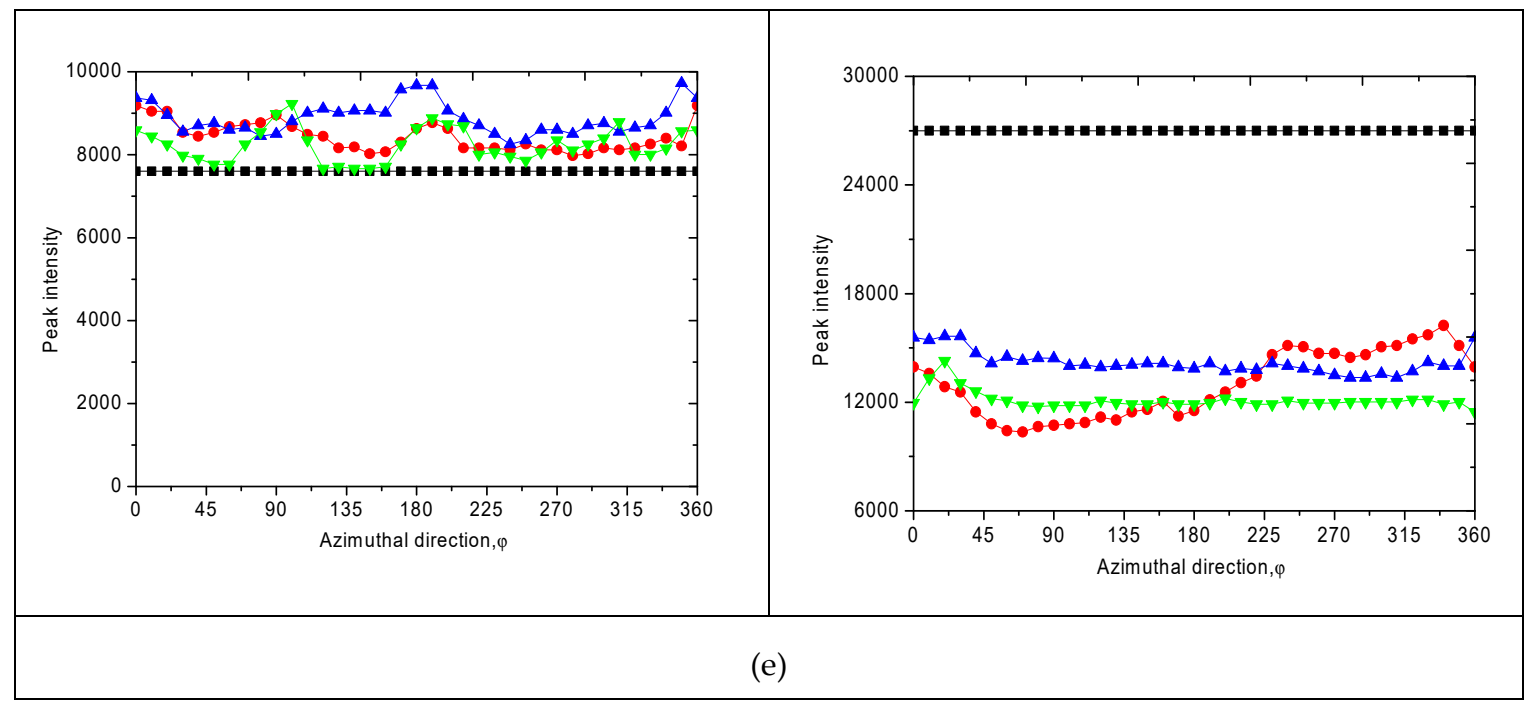

Figure 3. Azimuthal variations in the intensity of diffraction reflections (black line - initial sample; red line - irradiated by $\mathrm{Kr}^{13+}$ ions; blue line - irradiated by $\mathrm{Kr}^{14+}$ ions; green line - irradiated by $\mathrm{Kr}^{15+}$ ions): (a) $5.0 \times 10^{10} \mathrm{ion} / \mathrm{cm}^{2}$ ): (b) $7.5 \times 10^{10} \mathrm{ion} / \mathrm{cm}^{2}$; (c) $1.0 \times 10^{11} \mathrm{ion} / \mathrm{cm}^{2}$; (d) $2.5 \times 10^{11} \mathrm{ion} / \mathrm{cm}^{2}$; (e) $5.0 \times 10^{11} \mathrm{ion} / \mathrm{cm}^{2}$.

Figures 6 and 7: Fluences of $2.5 \times 10^{11}$ ions $/ \mathrm{cm}^{2}$ and $5 \times 10^{11}$ ions $/ \mathrm{cm}^{2}$ respectively

At these higher fluences we observe azimuthal anisotropy in the intensity of the peak at $2 \theta=26^{\circ}$, and a qualitative change in the $\mathrm{X}$-ray diffraction pattern in the amorphous phase, for all but the third picture in Figure 6, to which we will return later.

In the other five pictures, in the region $2 \theta=5-12^{\circ}$, in addition to the meridional reflections, new diffraction reflections appear, broadly centered around the equator, with azimuthal angular sizes of approximately $\pm 20^{\circ}$ either side, as can be seen in Figure 3d (red and blue lines) and Figure 3e (red, blue, and green lines). In the polar coordinate system $(2 \theta, \phi)$ these form a cross, oriented broadly along the meridian and equator, signaling the presence of spiral atropisomers. As these are in the amorphous zone, they must lie within latent tracks, in contrast to those observed earlier in overlap areas on the periphery of single tracks $[22,30]$. These new $\mathrm{X}$-ray patterns can be understood as resulting from tracks overlapping to such an extent that the whole film has become 'overlapped track', with interchain cross-linking occurring throughout the entire film. Since the values of angles in direct space are the same as those in the reciprocal space [33], this range of angles $\left(90^{\circ} \pm 20^{\circ}\right)$ indicates the presence of three types of spiral atropisomers, of inward $\left(\phi<90^{\circ}\right)$, outward $\left(\phi>90^{\circ}\right)$ and cylindrical $\left(\phi=90^{\circ}\right)$ helicity.

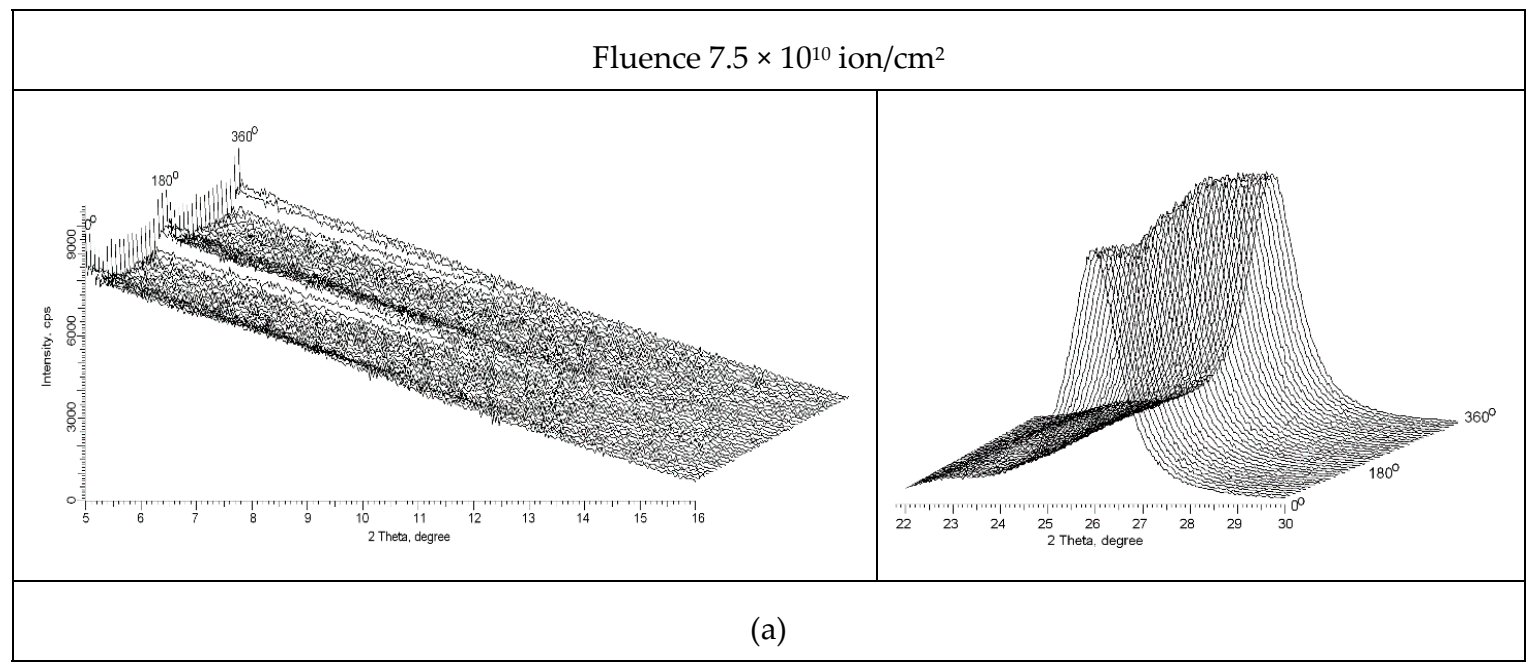

Figure 4. Cont. 


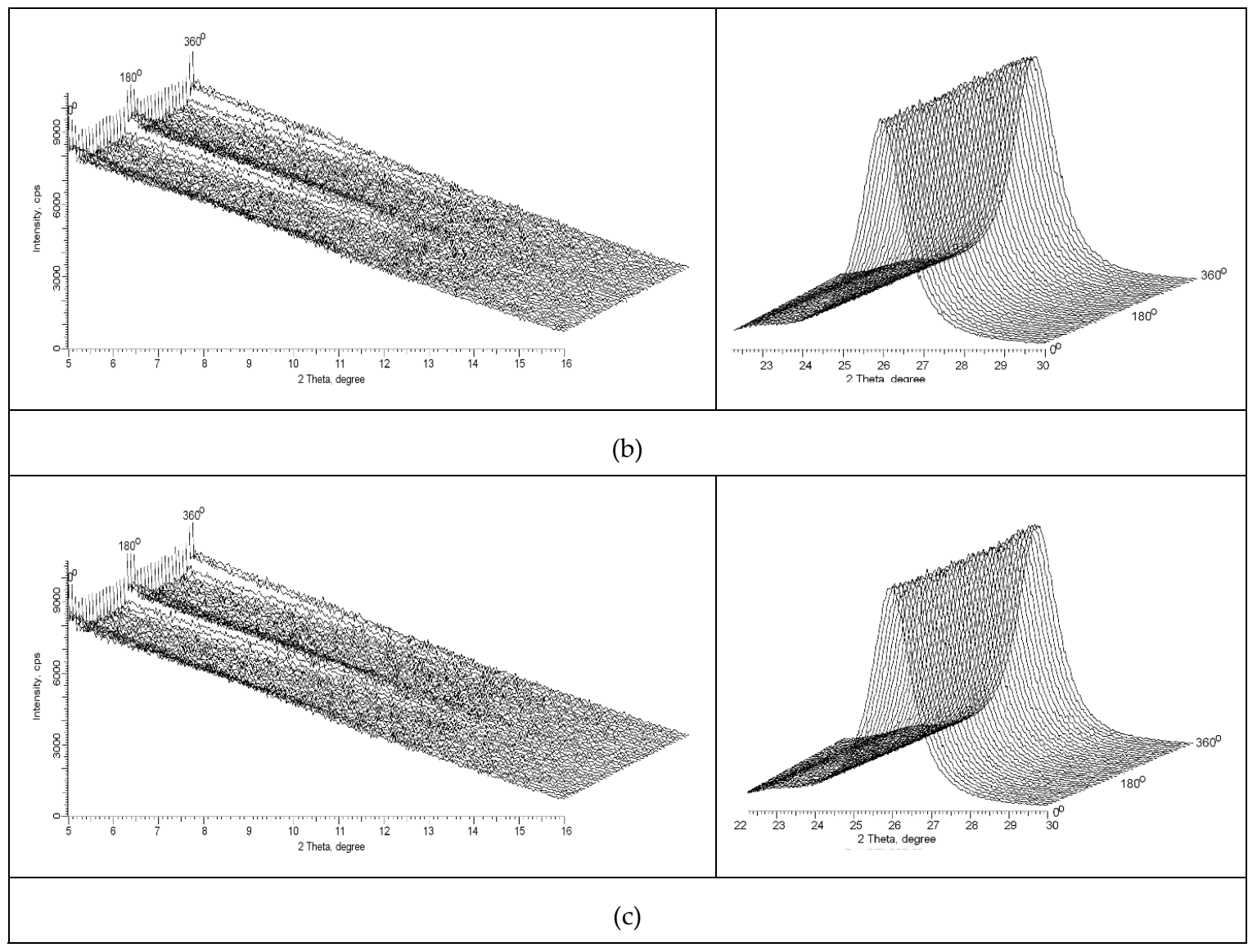

Figure 4. X-ray diffraction patterns of test samples polymer films: (a) irradiated $\mathrm{Kr}^{13+}$ ions; (b) irradiated $\mathrm{Kr}^{14+}$ ions; (c) irradiated $\mathrm{Kr}^{15+}$ ions.

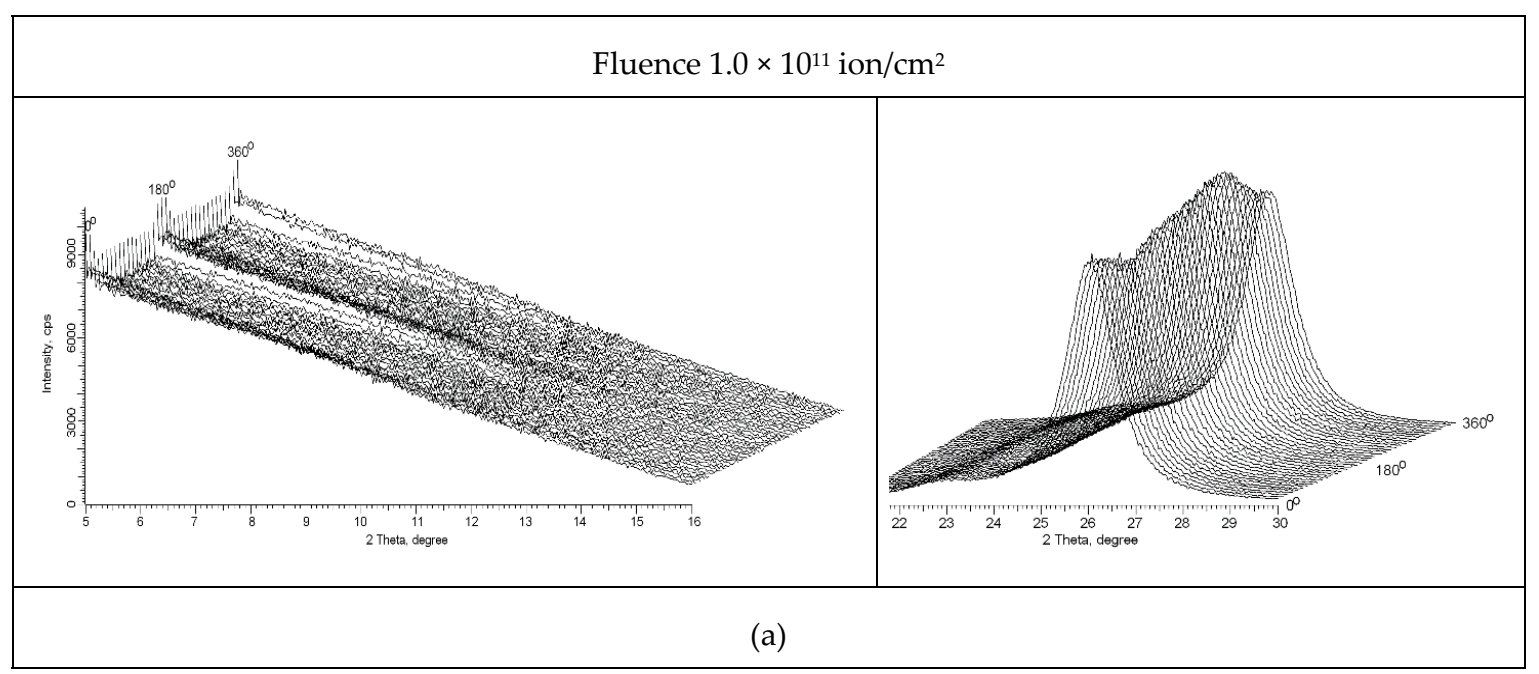

Figure 5. Cont. 


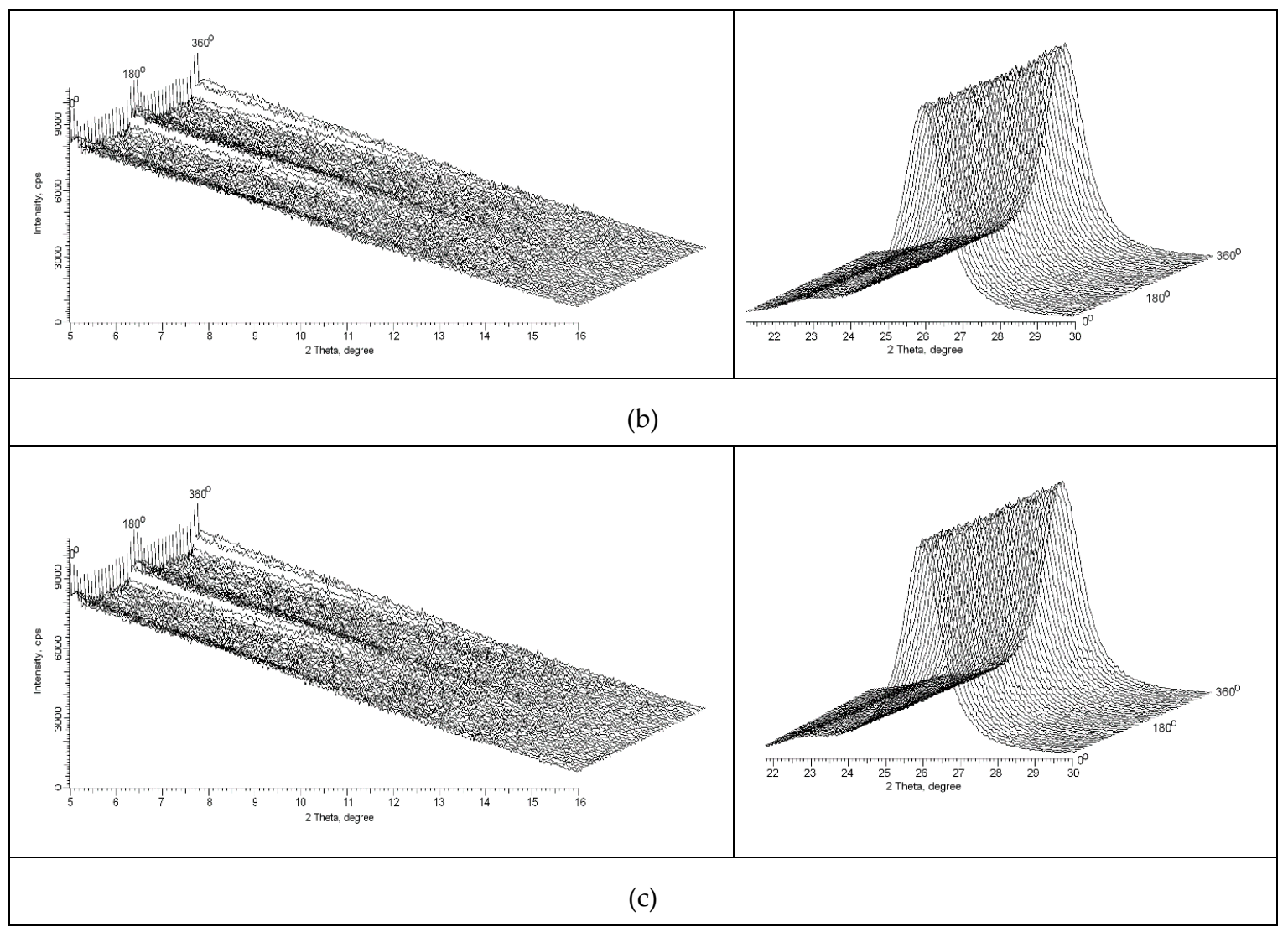

Figure 5. X-ray diffraction patterns of test samples polymer films: (a) irradiated $\mathrm{Kr}^{13+}$ ions; (b) irradiated $\mathrm{Kr}^{14+}$ ions; (c) irradiated $\mathrm{Kr}^{15+}$ ions.

The third picture in Figure $6\left(\mathrm{Kr}^{15+}\right.$ for a fluence of $2.5 \times 10^{11} \mathrm{ions} / \mathrm{cm}^{2}$, Figure $3 \mathrm{~d}$ green lines) is qualitatively similar to the set of five described above, with an azimuthally isotropic peak at $2 \theta=$ $26^{\circ}$ in the crystalline phase and an amorphous phase meridional reflection at $2 \theta=5-12^{\circ}$. In this case, however, the crystalline phase intensity peak at $2 \theta=26^{\circ}$ has dropped by approximately $25 \%$. This indicates an increase in stresses transferred along the PET molecular backbone to the crystalline phase due to an increase in the induced ordering in the amorphous phase (as was seen in [22]) - but here there is no corresponding increase in the intensity of the amorphous meridional reflection. In addition, the spiral atropisomers seen in the amorphous zone for lower ion charges at this fluence (Figure $3 \mathrm{~d}$, red and blue lines) have disappeared. These observations can be understood as due to a reduction in the temporal stability of the rotamers to below the threshold for X-ray observation, as was also seen at lower fluences (Figures 6 and 7). Despite being invisible in the X-ray pattern, the rotamers cause stresses which are transmitted along the molecular backbone, leaving a signature in the reduction in intensity of the X-ray peak at $2 \theta=26^{\circ}$.

Figure 8 shows schematically a visualization of the process of induced ordering in the residual electric field. Thin blue horizontal lines indicate the axes of chain molecules, lying mainly along the direction of movement of the film during its production. As mentioned above (Section 2.1), in the amorphous phase of the pristine film, benzene-carboxyl units are oriented in a random manner around the axes of chain molecules, as shown in Figure 8a by different projections of benzene rings with carboxyl units. 


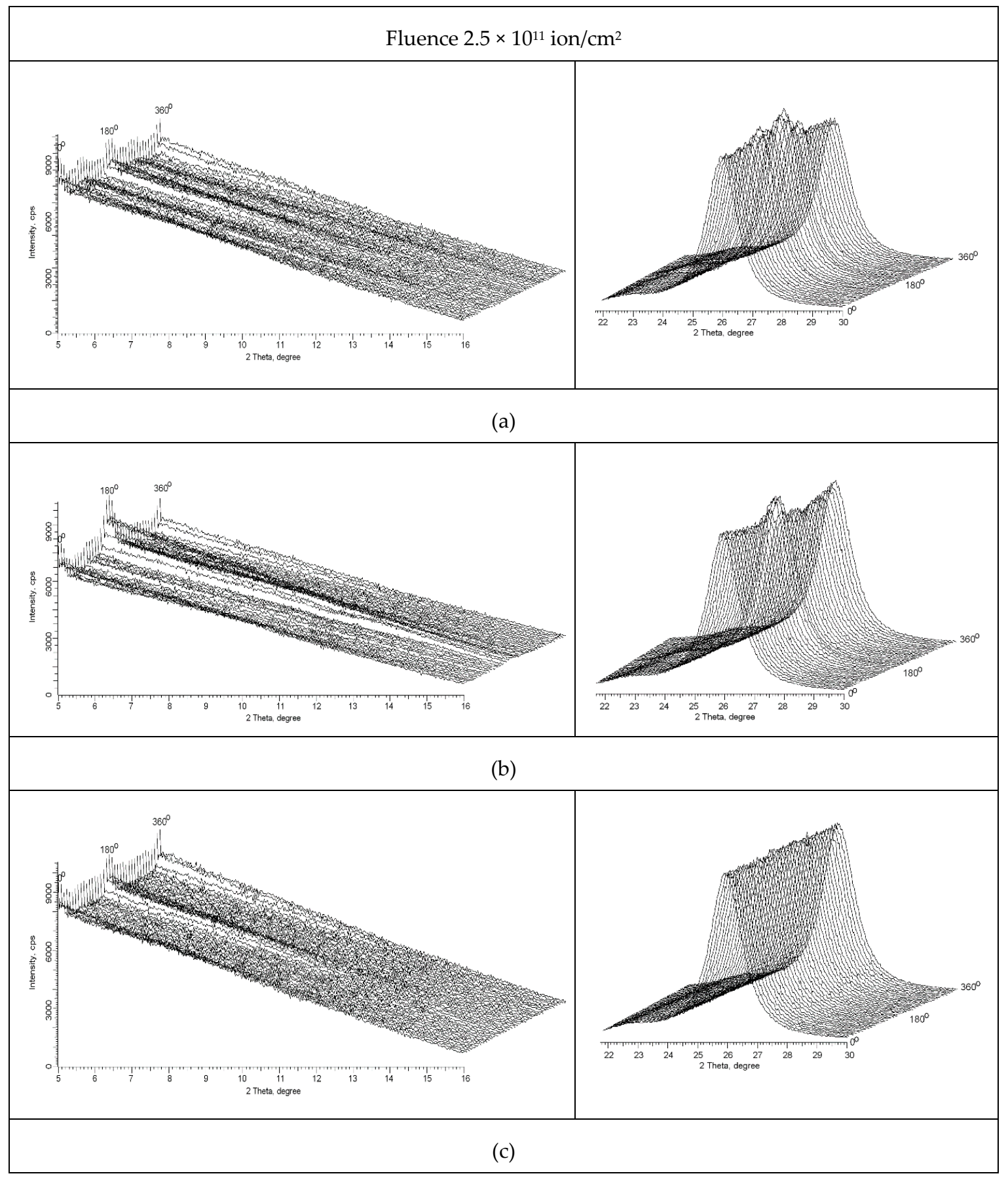

Figure 6. X-ray diffraction patterns of test samples polymer films: (a) irradiated $\mathrm{Kr}^{13+}$ ions; (b) irradiated $\mathrm{Kr}^{14+}$ ions; (c) irradiated $\mathrm{Kr}^{15+}$ ions.

Figure $8 \mathrm{~b}$ shows the rotational ordering of benzene-carboxyl subunits under the influence of the cylindrical residual electric field $E$ (red arrow) of the latent track. These units are bound within the chain molecule by covalent forces and are not able to make linear movements (except for slow creep-like movements [30]), but, being linked to the chain by $\sigma$-hinges, they can rotate around the axis of the molecule. The combination of kinematic restrictions and rotation leads to the benzene-carboxyl units tending to move to maximize the projections of the dipole moments of the carboxyl groups onto the direction of the electric field vector $\boldsymbol{E}$. This results in the carboxyl groups becoming generally oriented in the same direction, as shown in Figure $8 b$. 


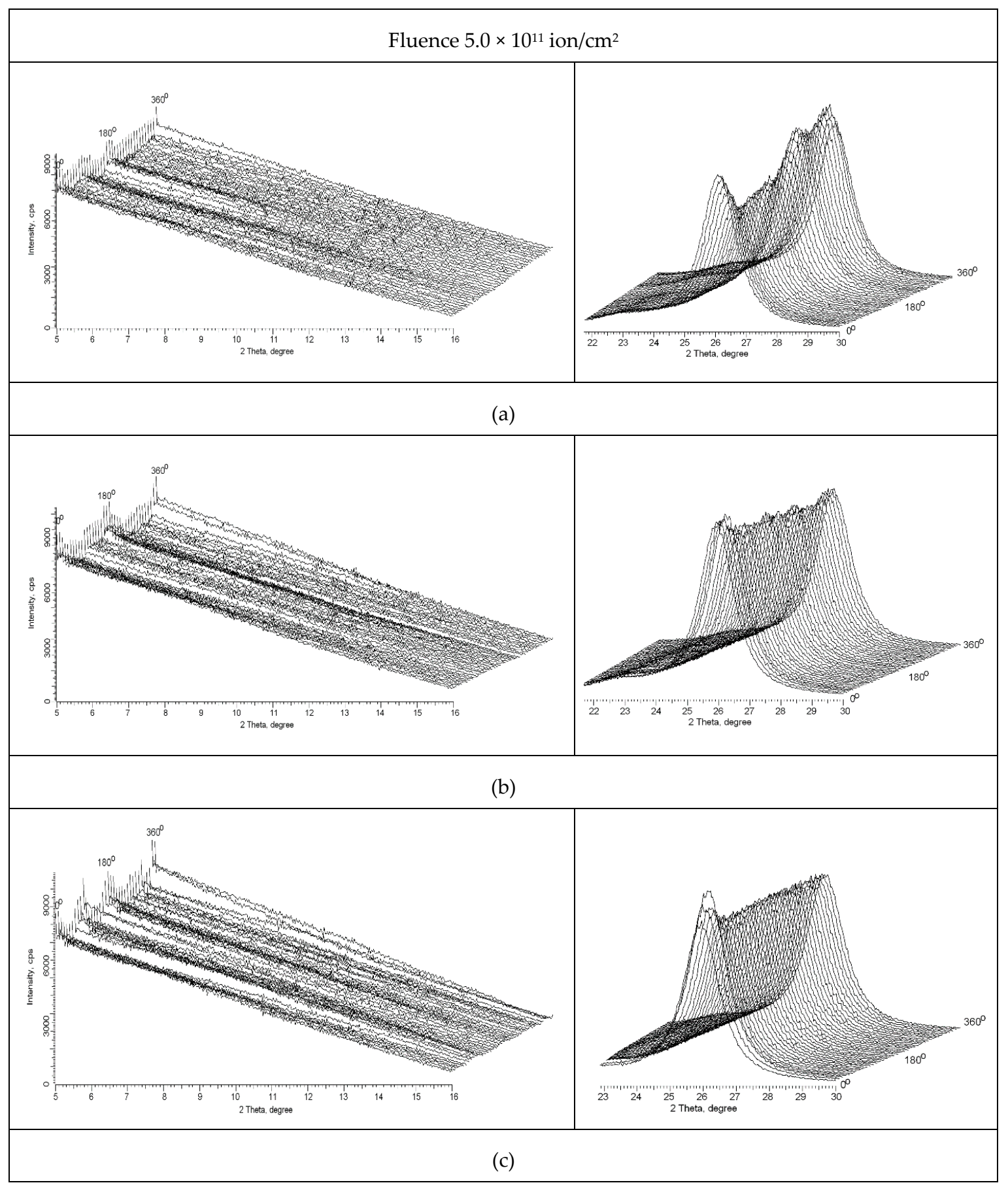

Figure 7. X-ray diffraction patterns of test samples polymer films: (a) irradiated $\mathrm{Kr}^{13+}$ ions; (b) irradiated $\mathrm{Kr}^{14+}$ ions; (c) irradiated $\mathrm{Kr}^{15+}$ ions.

The appearance of helicoid structures occurs through self-assembly of repeat units of PET [48]. Another example of self-assembly of chain molecules with the formation of nanopores is shown in [49]. 


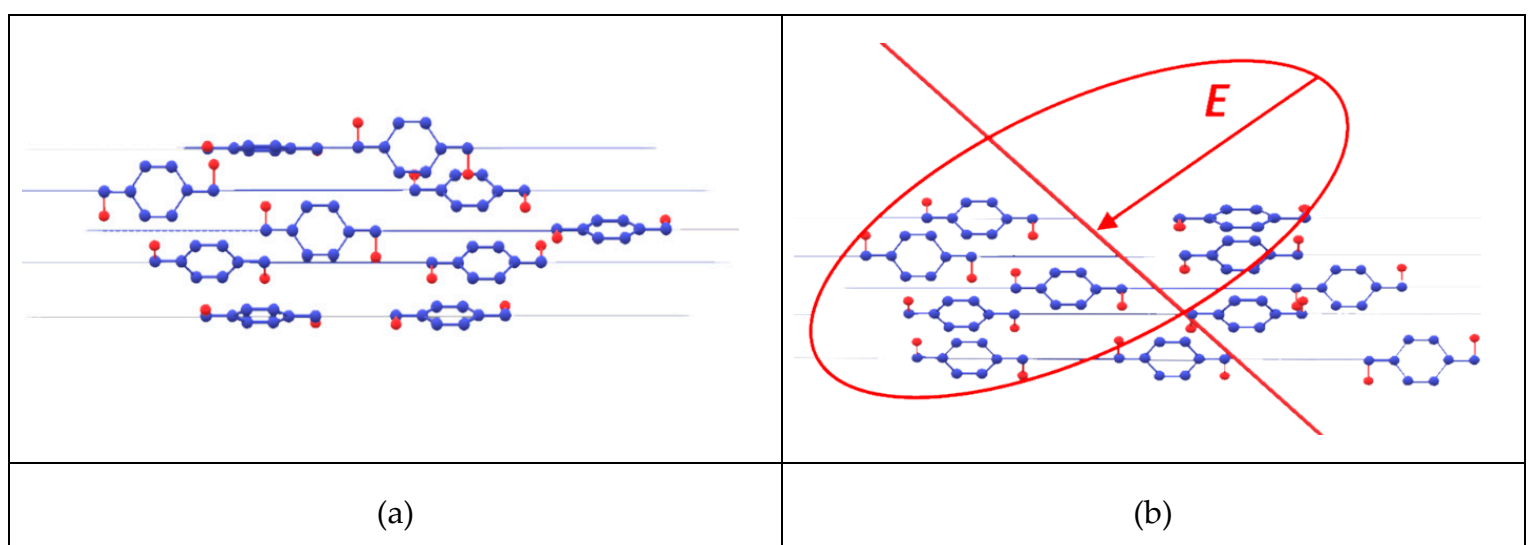

Figure 8. Schematic representation of the orientation of benzene-carboxyl units of the amorphous phase of the PET film: (a) pristine; (b) in the residual electric field of the latent track.

\section{Conclusions}

The results of our studies clearly demonstrate that post-irradiation structural changes in PET films are affected by the initial charge of the irradiating heavy ions. We used the fluence associated with the onset of the overlapping of individual latent tracks to estimate the radii of latent tracks in PET to be $5 \mathrm{~nm}$ for $\mathrm{Ar}^{8+}, 18 \mathrm{~nm}$ for $\mathrm{Kr}^{13+}$ and $22 \mathrm{~nm}$ for $\mathrm{Kr}^{14+}$. Our results confirm our previous conclusion that with the onset of the overlap of the residual electric fields of latent tracks, rotamers are formed in the overlap regions. Restrictions on interconversion between rotamers are sometimes sufficient to allow the formation of long-lived atropisomers whose spiral signatures can be observed in X-ray diffractograms.

At high enough fluences and/or ion charges, all latent tracks overlap, and spiral conformations are seen throughout the entire irradiated film. The dipole-dipole nature of the interchain cross-linking that creates these rotamers means that this cross-linking is reversible [22,30]. This contrasts with the well-known chemical cross-linking of polymer chain molecules under irradiation, caused by $\delta$-electrons and secondary knock-on electrons [50,51], which involves the breaking and formation of chemical bonds. In our samples, a question arises as to whether it is useful to continue to speak about overlapping latent tracks, or makes more sense to speak about a dipole-dipole cross-linked irradiated film.

Author Contributions: Conceptualization, A.Z.T., M.V.Z.; methodology, A.Z.T., M.V.Z. and A.L.K.; formal analysis, A.L.K., M.V.Z.; investigation, A.Z.T., F.E.H., M.V.Z.; resources, M.V.Z.; writing-original draft preparation, review, and editing, A.Z.T., F.E.H., A.L.K., M.V.Z.; visualization, A.Z.T., A.L.K.; supervision, M.V.Z.; project administration, M.V.Z.; funding acquisition, M.V.Z. All authors have read and agreed to the published version of the manuscript.

Funding: This research received no external funding and F.E. Harrison took part in this research as a volunteer.

Acknowledgments: The authors would like to express their gratitude to P.Y. Apel for a helpful discussion when developing the objectives of this research.

Conflicts of Interest: The authors declare no conflict of interest.

\section{References}

1. Bush, S.N.; Volta, T.T.; Martin, C.R. Chemical Sensing and Chemoresponsive Pumping with Conical-Pore Polymeric Membranes. Nanomaterials 2020, 10, 571. [CrossRef]

2. Syrtsova, D.A.; Teplyakov, V.V. High-Energy Ion Treatment of Lavsan Films Followed by Controlled Track Etching to Obtain Asymmetric Gas-Separation Membranes. Russ. J. Appl. Chem. 2019, 92, 150-158. [CrossRef]

3. Vacik, J.; Hnatowicz, V.; Havranek, V.; Fink, D.; Apel, P.; Horak, P.; Ceccio, G.; Cannavo, A.; Torrisi, A. Ion track etching in polyethylene-terephthalate studied by charge particle transmission technique. Radiat. Eff. Defects Solids 2019, 174, 148-157. [CrossRef] 
4. Ceccio, G.; Cannavò, A.; Horak, P.; Torrisi, A.; Hnatowicz, V.; Apel, P.Y.; Vacik, J. Lithium encapsulation in etched nuclear pores in polyethylene terephthalate. Nucl. Instrum. Methods Phys. Res. Sect. B Beam Interact. Mater. Atoms 2020, 469, 19-23. [CrossRef]

5. Apel, P.Y. Fabrication of functional micro- and nanoporous materials from polymers modified by swift heavy ions. Radiat. Phys. Chem. 2019, 159, 25-34. [CrossRef]

6. Apel, P.Y.; Bobreshova, O.V.; Volkov, A.V.; Nikonenko, V.V.; Stenina, I.A.; Filippov, A.N.; Yampolskii, Y.P.; Yaroslavtsev, A.B.; Volkov, V.V. Prospects of Membrane Science Development. Membr. Membr. Technol. 2019, 1,45-63. [CrossRef]

7. Kaya, D.; Keçeci, K. Review-Track-Etched Nanoporous Polymer Membranes as Sensors: A Review. J. Electrochem. Soc. 2020, 167, 037543. [CrossRef]

8. Fiodorov, V.A.; Vasiliev, A.B.; Nazmov, V.P.; Goldenberg, B.G.; Bedin, S.A.; Berezkin, V.V. Optical Properties of Regular Track-Etched Poly(ethylene terephthalate) Membranes. Membr. Membr. Technol. 2019, 1, $27-30$. [CrossRef]

9. Li, G.; Wang, J.; Hou, D.; Bai, Y.; Liu, H. Fabrication and performance of PET mesh enhanced cellulose acetate membranes for forward osmosis. J. Environ. Sci. 2016, 45, 7-17. [CrossRef]

10. Apel, P.Y. Track etching technique in membrane technology. Radiat. Meas. 2001, 34, 559-566. [CrossRef]

11. Takahashi, S.; Yoshida, M.; Asano, M.; Notomi, M.; Nakagawa, T. Characterizations of heavy ion irradiated PET membranes. Nucl. Instrum. Methods Phys. Res. Sect. B Beam Interact. Mater. Atoms 2004, 217, $435-441$. [CrossRef]

12. Miyazaki, T.; Takenaka, M. Precise small-angle X-ray scattering evaluation of the pore structures in track-etched membranes: Comparison with other convenient evaluation methods. Nucl. Instrum. Methods Phys. Res. Sect. B Beam Interact. Mater. Atoms 2017, 394, 121-125. [CrossRef]

13. Bomko, V.; Burban, A.; Kobets, A.; Kryshtal, A.P.; Vorobyova, I.; Zajtsev, B. Initial stage of etching through pores in PET films irradiated by Ar ions. Nucl. Instrum. Methods Phys. Res. Sect. B Beam Interact. Mater. Atoms 2008, 266, 256-261. [CrossRef]

14. Steckenreiter, T.; Balanzat, E.; Fuess, H.; Trautmann, C. Chemical modifications of PET induced by swift heavy ions. Nucl. Instrum. Methods Phys. Res. Sect. B Beam Interact. Mater. Atoms 1997, 131, 159-166. [CrossRef]

15. Apel, P.Y.; Blonskaya, I.; Oganessian, V.; Orelovitch, O.; Trautmann, C. Morphology of latent and etched heavy ion tracks in radiation resistant polymers polyimide and poly(ethylene naphthalate). Nucl. Instrum. Methods Phys. Res. Sect. B Beam Interact. Mater. Atoms 2001, 185, 216-221. [CrossRef]

16. Maletić, S.; Cerovic, D.D.; Dojcilovic, J.R. A study of structural and spectral properties of ion-beam modified polyethylene terephthalate membrane. Nucl. Instrum. Methods Phys. Res. Sect. B Beam Interact. Mater. Atoms 2019, 441, 1-7. [CrossRef]

17. Siwy, Z.; Apel, P.Y.; Dobrev, D.; Neumann, R.; Spohr, R.; Trautmann, C.; Voss, K. Ion transport through asymmetric nanopores prepared by ion track etching. Nucl. Instrum. Methods Phys. Res. Sect. B Beam Interact. Mater. Atoms 2003, 208, 143-148. [CrossRef]

18. Wen, Q.; Yan, D.; Liu, F.; Wang, M.; Ling, Y.; Wang, P.; Kluth, P.; Schauries, D.; Trautmann, C.; Apel, P.; et al. Highly Selective Ionic Transport through Subnanometer Pores in Polymer Films. Adv. Funct. Mater. 2016, 26, 5796-5803. [CrossRef]

19. Wang, P.; Wang, M.; Liu, F.; Ding, S.; Wang, X.; Du, G.; Liu, J.; Apel, P.; Kluth, P.; Trautmann, C.; et al. Ultrafast ion sieving using nanoporous polymeric membranes. Nat. Commun. 2018, 9, 569. [CrossRef]

20. Berezkin, V.V.; Nechaev, A.N.; Fomichev, S.V.; Mchedlishvili, B.V. Nuclear filters with ion-selective properties. Colloid J. USSR 1991, 53, 292-295.

21. Siwy, Z.; Kosińska, I.D.; Fuliński, A.; Martin, C.R. Asymmetric diffusion through synthetic nanopores. Phys. Rev. Lett. 2005, 94, 048102. [CrossRef] [PubMed]

22. Apel, P.Y.; Blonskaya, I.V.; Ivanov, O.M.; Kristavchuk, O.V.; Lizunov, N.E.; Nechaev, A.N.; Orelovich, O.L.; Polezhaeva, O.A.; Dmitriev, S.N. Creation of Ion-Selective Membranes from Polyethylene Terephthalate Films Irradiated with Heavy Ions: Critical Parameters of the Process. Membr. Membr. Technol. 2020, 2, 98-108. [CrossRef]

23. Zdorovets, M.; Kozlovskiy, A.; Harrison, F.; Tuleushev, A. Induced ordering in polyethylene terephthalate films irradiated with Ar ions with an energy of $70 \mathrm{MeV}$. Surf. Coat. Technol. 2020, 386, 125490. [CrossRef] 
24. Liu, F.; Wang, M.; Wang, X.; Wang, P.; Shen, W.; Ding, S.; Wang, Y. Fabrication and application of nanoporous polymer ion-track membranes. Nanotechnology 2018, 30, 052001. [CrossRef]

25. Trautmann, C.; Schwartz, K.; Costantini, J.; Steckenreiter, T.; Toulemonde, M. Radiation defects in lithium fluoride induced by heavy ions. Nucl. Instrum. Methods Phys. Res. Sect. B Beam Interact. Mater. Atoms 1998, 146, 367-378. [CrossRef]

26. Bowman, M.K.; Becker, D.; Sevilla, M.D.; Zimbrick, J.D. Track structure in DNA irradiated with heavy ions. Radiat. Res. 2005, 163, 447-454. [CrossRef]

27. Zhu, Z.; Sun, Y.; Liu, C.; Liu, J.; Jin, Y. Chemical modifications of polymer films induced by high energy heavy ions. Nucl. Instrum. Methods Phys. Res. Sect. B Beam Interact. Mater. Atoms 2002, 193, 271-277. [CrossRef]

28. Apel, P.Y.; Schulz, A.; Spohr, R.; Trautmann, C.; Vutsadakis, V. Tracks of very heavy ions in polymers. Nucl. Instrum. Methods Phys. Res. Sect. B Beam Interact. Mater. Atoms 1997, 131, 55-63. [CrossRef]

29. Sessler, G.M. Physical Principles of Electrets; Springer: Berlin/Heidelberg, Germany, 1980; pp. $13-80$.

30. Tuleushev, A.; Zdorovets, M.V.; Kozlovskiy, A.L.; Harrison, F. Induced Spirals in Polyethylene Terephthalate Films Irradiated with Ar Ions with an Energy of $70 \mathrm{MeV}$. Crystals 2020, 10, 427. [CrossRef]

31. Crompton, T.R. Chemical Analysis of Additives in Plastics; Elsevier: Amsterdam, the Netherlands, 2016; Volume 46.

32. Daubeny, R.d.P.; Bunn, C.W.; Brown, C.J. The crystal structure of polyethylene terephthalate. In Proceedings of the Royal Society of London. Series A. Mathematical and Physical Sciences; The Royal Society: London, UK, 1954; pp. 531-542.

33. Weinstein, B.K. X-ray Diffraction by Chain Molecules; Nauka (Publishing House of the USSR Academy of Sciences): Moscow, Russia, 1963.

34. Durell, M.; Macdonald, J.; Trolley, D.; Wehrum, A.; Jukes, P.C.; Jones, R.; Walker, C.J.; Brown, S. The role of surface-induced ordering in the crystallisation of PET films. EPL Europhys. Lett. 2002, 58, 844-850. [CrossRef]

35. Loew, L.M.; Sacher, E. Use of molecular orbital theory potential energy surfaces in determining polymer conformations. I. Poly (ethylene terephthalate). J. Macromol. Sci. Part B 1978, 15, 619-634. [CrossRef]

36. Ouchi, I. Anisotropic Absorption and Reflection Spectra of Poly (ethylene terephthalate) Films in Ultraviolet Region. Polym. J. 1983, 15, 225-243. [CrossRef]

37. Arnott, S.; Wonacott, A.J. The refinement of the crystal and molecular structures of polymers using X-ray data and stereochemical constraints. Polymer 1966, 7, 157. [CrossRef]

38. Bailey, M.; Brown, C.J. The crystal structure of terephthalic acid. Acta Cryst. 1967, 22, 387. [CrossRef]

39. Lunazzi, L.; Ticca, A.; Macciantelli, D.; Spunta, G. Solvent influence on the rotational isomerism in terephthalaldehyde. J. Chem. Soc. Perkin II 1976, 1121.

40. Sacher, E. The possibility of quantum mechanical effects in polymeric systems. J. Macromol. Sci. Part B Phys. 1976, 12, 603-608. [CrossRef]

41. Hofsäss, H.; Zhang, K.; Mutzke, A. Simulation of ion beam sputtering with SDTrimSP, TRIDYN and SRIM. Appl. Surf. Sci. 2014, 310, 134-141.

42. Hill, R.J.; Howard, C.J. Quantitative phase analysis from neutron powder diffraction data using the Rietveld method. J. Appl. Crystallogr. 1987, 20, 467-474. [CrossRef]

43. Knupp, C.; Squire, J.M. HELIX: A Helical Diffraction Simulation Program by Carlo Knupp \& John M. Squire. J. Appl. Crystallogr. 2004, 37, 832-835.

44. Abu Saleh, S.; Eyal, Y. Porous tracks along wakes of swift uranium ions in polyimide. Appl. Phys. Lett. 2004, 85, 2529. [CrossRef]

45. Ciesla, K.; Starosta, W. Heavy ions track structure in a PETP. Nucl. Instrum. Methods Phys. Res. Sect. B Beam Interact. Mater. Atoms 1995, 105, 115-119. [CrossRef]

46. Apel, P.Y.; Schulz, A.; Spohr, R.; Trautmann, C.; Vutsadakis, V. Track size and track structure in polymer irradiated by heavy ions. Nucl. Instrum. Methods Phys. Res. Sect. B Beam Interact. Mater. Atoms 1998, 146, 468-474. [CrossRef]

47. Moss, G.P. Basic terminology of stereochemistry (IUPAC Recommendations 1996). Pure Appl. Chem. 1996, 68, 2193-2222. [CrossRef]

48. Wang, Y.; He, Y.; Yu, Z.; Gao, J.; Brinck, S.T.; Slebodnick, C.; Fahs, G.B.; Zanelotti, C.J.; Hegde, M.; Moore, R.B.; et al. Double helical conformation and extreme rigidity in a rodlike polyelectrolyte. Nat. Commun. 2019, 10, 801. [CrossRef] [PubMed] 
49. Zhou, X.; Liu, G.; Yamato, K.; Shen, Y.; Cheng, R.; Wei, X.; Bai, W.; Gao, Y.; Li, H.; Liu, Y.; et al. Self-assembling subnanometer pores with unusual mass-transport properties. Nat. Commun. 2012, 3, 949. [CrossRef] [PubMed]

50. Kravets, L.I.; Apel, P.Y. Heavy Ion Track Sensitization in Polypropylene; No. JINR-R-18-95-315; Joint Institute for Nuclear Research: Dubna, Russia, 1995.

51. Apel, P.Y.; Spohr, R.; Trautmann, C.; Vutsadakis, V. Track structure in polyethylene terephthalate irradiated by heavy ions: Let dependence of track diameter. Radiat. Meas. 1999, 31, 51-56. [CrossRef]

(C) 2020 by the authors. Licensee MDPI, Basel, Switzerland. This article is an open access article distributed under the terms and conditions of the Creative Commons Attribution (CC BY) license (http://creativecommons.org/licenses/by/4.0/). 